\title{
Meio ambiente e cooperação: os valores cooperativos como pressuposto de sustentabilidade
}

\author{
José Eduardo Miranda', Antônio Luiz Curtis², \\ Emerson Ferreira da Fonseca², Eriane Araújo Teixeira², \\ Fernando Nascimento Lille2, Marcos André Gomes da Penha², \\ Pedro Paulo Fonseca Bicas², Sthephanie Karla Darós², \\ Tauã Lima Verdan², Vânia Gomes²
}

Sumário: Considerações preliminares; I. Compreendendo o significado de meio ambiente; II. Meio ambiente natural e crise: um futuro questionável; III. A detração ambiental pelo inadequado valor do humano; IV. A Cooperação na base da proteção ambiental: A conduta cooperacionista prevista pela Declaração do Rio; V. Os valores cooperativos como pressuposto de sustentabilidade: a necessidade de altercação da postura do humano diante do meio ambiente natural; Referências Bilbioigráficas

Resumo: Ademais de estabelecer a compreensão do significado de meio ambiente, o presente trabalho esclarece que a detração do meio ambiente decorre na minimização do valor que o homem dedica à natureza. Neste sentido, e tendo em vista a crise ambiental que enfrenta a humanidade, o futuro é visto com dúvida. Oferece-se, então, a alternativa cooperativa imposta pela Declaração do Rio, e se apresenta os valores cooperativos como pressuposto de sustentabilidade.

Palavras-chave: Sustentabilidade; Cooperação; Valores cooperativos.

Abstract: In addition to establishing an understanding of the meaning of environment, the work clarifies that the environmental damage resulting value gives the minimization of the man dedicated to nature. In this regard, bearing in mind the environmental crisis confrontation served humanity, the future is

1 Doutor em Direito; Coordenador do Curso de Direito do Centro Universitário São Camilo-Espírito Santo; Coordenador do Projeto de Pesquisa Os valores cooperativos como instrumento de (re)construção social.

2 Acadêmicos do Curso de Direito do Centro Universitário São Camilo-Espírito Santo; Membros do Grupo de Pesquisa Os valores cooperativos como instrumento de (re)construção social. 
viewed with doubt. It also offers, the alternative cooperative established by the Declaration of Rio and cooperative values is presented as a precondition for sustainability.

Keywords: Sustainability; Cooperation; Cooperative values. 


\section{Considerações preliminares}

Mercenário de interesses materiais que não acabam, o homem galopa freneticamente em busca de um crescimento econômico a qualquer preço. Quanto mais tem, mais quer. Quanto mais quer, menos pondera a atitude danosa que desenvolve na extração ilimitada e incontrolada dos recursos naturais.

O meio ambiente, assim, se transformou em vítima da sagacidade de um homem que o destrói, despreocupado com a importância que tem para o seu presente, e da preponderância que tem para o seu próprio futuro.

Na medida em que danifica o meio ambiente natural, o homem sofre conseqüências imediatas cuja responsabilidade é incapaz de perceber que é sua. Derruba árvores, queima florestas, polui descontroladamente. É perseguido administrativa e judicialmente. Sofre sanções e paga multas, mas reincide na detração ambiental, indiferente ao preço da pena.

A lei, portanto, se é eficiente, padece de eficácia...

Assim, o amanhã da humanidade está sub-rogado ao estabelecimento de uma cultura de desenvolvimento sustentável, própria ao engajamento do homem com o meio ambiente natural, de maneira que o utilize, sem eliminá-lo do contexto de vida.

Esta cultura, se entende, emana da prática dos valores cooperativos, próprios à transformação completa do homem, e ao estabelecimento de uma nova postura do humano frente aos diferentes fenômenos que se desenvolvem no decorrer de sua existência terrena.

\section{Compreendendo o significado de meio ambiente}

Distante do interesse de percorrer pela identidade conceitual que a literatura costuma atribuir às expressões meio e ambiente ${ }^{3}$, importante, aqui, estabelecer que o meio ambiente diz respeito aos diferentes contextos e situações que cingem a existência humana. Esta compreensão, ao contrario de generalista, converge com os termos da pauta normativa do inciso I, do artigo $3 .^{\circ}$, da Lei . $^{\circ}$ 6.938/81, que define o meio ambiente como «o conjunto de condições, leis, influências e interações

3 Sobre o tema, ver Da Silva, José Afonso. Direito Ambiental Constitucional. 5. a ed., São Paulo: Malheiros, 2004; Fiorillo, Celso Antônio Pacheco. Curso de Direito Ambiental Brasileiro. 11. ${ }^{a}$ ed., São Paulo: Saraiva, 2010; Machado, Paulo Affonso Leme. Direito Ambiental Brasileiro. 18. ${ }^{a}$ ed. São Paulo: Malheiros, 2010. 
de ordem física, química e biológica, que permite, abriga e rege a vida em todas as suas formas ${ }^{4}$.

De outra forma, e sob o abrigo da orientação doutrinária, o meio ambiente costuma ser distinguindo em quatro categorias que perfazem um todo, e compreendem objeto de proteção do ordenamento jurídico, quais sejam: o meio ambiente natural, o meio ambiente artificial, o meio ambiente cultural e o meio ambiente do trabalho ${ }^{5}$.

O meio ambiente natural, também denominado de meio ambiente físico, "concentra o fenômeno homeostase, consistente no equilíbrio entre os seres vivos e o meio em que vivem ${ }^{6}$. Em linhas gerais, podese dizer que o meio ambiente natural é aquele que existe sem a influência do homem, como a flora, a fauna, o solo, a água, a vida, etc.

Por sua vez, o meio ambiente artificial resulta da interação do homem com o meio ambiente natural, e é constituído pelo espaço urbano propriamente dito, a exemplo dos edifícios, das ruas, das praças, dos parques, etc. ${ }^{7}$.

Já, o meio ambiente cultural, também proveniente da influência do homem sobre o meio ambiente natural, pode ser dividido em bens de natureza material (documentos e objetos de importância cultural) e bens de natureza imaterial (os costumes de uma determinada sociedade). Sob esta ótica, o meio ambiente cultural engloba o patrimônio histórico, cientifico, artístico, paisagístico, arqueológico, turístico, etc.

Finalmente, o meio ambiente do trabalho, é aquele espaço que tem como base a relação do trabalhador com o meio que o cerca em seu ambiente de trabalho. Neste sentido, o conjunto de múltiplos fatores e bens de uma entidade organizada, "objetos de direitos relativos à saúde e integridade física dos trabalhadores» ${ }^{8}$.

\section{Meio ambiente natural em crise: um futuro questionável}

Em decorrência de uma nova sistemática, norteada, especialmente, pelos fundamentos e ideários de globalização das questões ambientais, como fruto das importantes conseqüências econômicas acarretadas

4 Brasil. Lei 6.938/81. Disponível em www.planaltolgov.br; Acesso em 28 de junho de 2010.

5 Smanio, Gianpaolo Poggio. Interesses difusos e coletivos. 6. ${ }^{a}$ ed. São Paulo: MaIheiros, 2004. p. 91.

6 Fiorillo, 2010, p. 71.

7 Smanio, 2004, p. 91.

8 Smanio, 2004, p. 91. 
no mundo inteiro, novas prerrogativas passaram a integrar a vida do homem, dentre estas a relação entre a economia e o meio ambiente. Ante tais circunstâncias, a relação entre os vários organismos destinados a coibir os abusos ambientais estabeleceu, no decorrer da história, regulamentações legais que, progressivamente, se fortaleceram e passaram a integrar as Constituições dos Estados.

Neste contexto, a Carta da República Federativa do Brasil salvaguardou o direito ao meio ambiente ecologicamente equilibrado para todos, como aspecto integrante dos direitos fundamentais, uma vez que é sustentáculo da concepção e potencialização do princípio da dignidade da pessoa humana. Ainda, nesta trilha, o artigo 225, do Escrito constitucional brasileiro, preconiza que todos «têm direito ao meio ambiente ecologicamente equilibrado, bem de uso comum do povo e essencial à sadia qualidade de vida, impondo-se ao Poder Público e à coletividade o dever de defendê-lo e preservá-lo para as presentes e futuras gerações» ${ }^{9}$.

Por seguinte, urge sobrelevar que a detração do meio ambiente ganhou ênfase com o advento dos direitos da terceira geração, os quais materializaram as premissas de titularidade coletiva, consagraram o princípio da solidariedade e passaram a reconhecer os direitos humanos, enquanto valores fundamentais indisponíveis e inexauríveis.

Reconhecido como um direito difuso ${ }^{10}$, o meio ambiente natural equilibrado torna-se prerrogativa das presentes e futuras gerações, de maneira que se torna proibido o uso depreciativo dos recursos naturais.

Apesar do predomínio de gritos políticos, de leis extravagantes, de fiscalização questionável, o homem prossegue o maior malfeitor do meio ambiente natural, e sobre ele desenvolve um exercício de detração ininterrupta.

De outra forma, deve-se sublinhar que a aparente relevância que o homem dispensa à questão do meio ambiente natural não se apresenta como suficiente para reverter o quadro deplorável do inadequado consumo dos recursos naturais, eis que, ainda hoje, o meio ambiente natural é visto como um fornecedor ilimitado de recursos para o próprio homem, que negligencia as consequências produzidas por seu uso indevido, ou exagerado. Por assim dizer, a contínua exploração do meio

9 Brasil. Constituição da República Federativa do Brasil. 44 ed. São Paulo: Saraiva, 2010. p. 164.

10 Merece destaque que o direito ou interesse difuso «concerne a um universo maior do que o interesse coletivo, e pode, mesmo, concernir até toda a humanidade» (Mancuso, Rodolfo de Camargo. Interesses Difusos: conceito e legitimação para agir. 6. ${ }^{a}$ ed. São Paulo: RT, 2004. p. 84). 
ambiente natural gera efeitos em uma órbita diversa, que afetam, inclusive, a economia mundial, produzindo abalos e até mesmo desestruturando toda a sua base.

O meio ambiente natural continua vítima de danos alarmantes. Por isso, prematuro se mostra qualquer expectativa no sucesso de um brado de preservação como fruto do desenvolvimento sustentável, eis que, ainda agora, no apogeu do século XXI, vale para o homem aquilo que Ihe serve, Ihe é útil e pode ser absolutamente aproveitado, independente das implicações.

\section{A detração ambiental pelo inadequado valor do humano}

Com a chegada do século XXI, o meio ambiente natural tornouse um dos assuntos mais discutidos no cenário mundial. A justificativa para essa importância deve-se ao fato de que o futuro do planeta está ameaçado pelas consequências resultantes da intervenção humana na natureza.

Já se teve a oportunidade de manifestar, anteriormente, que o meio ambiente natural é concebido por uma visão holística, sistêmica, que o conceitua como o meio físico composto pela interação dos elementos naturais com as diversas formas de vida existentes. Por esta trilha, subtende-se que a natureza se mantém de uma relação equilibrada entre os fatores bióticos e os abióticos. Contudo, com o processo de degradação ambiental, iniciado há milhares de anos, o equilíbrio ecológico se mostra comprometido.

Desde o momento em que começou a conviver em grupos, o homem passou a intervir no meio natural a fim de obter as condições necessárias à sua sobrevivência e a de seus semelhantes. O problema intensificou-se com a Revolução Industrial. A introdução de máquinas nos meios de produção, a utilização dos meios de transportes movidos a combustíveis e o aumento populacional nos centros urbanos deflagraram diferentes formas de poluição que acabaram por macular o meio ambiente natural de forma gradativa.

Com o passar dos anos, a situação agravou-se. Desmatamentos, queimadas, uso de produtos químicos (agrotóxicos) nas atividades econômicas, caça e pesca predatórias, queima de combustíveis fósseis, lixo são exemplos de conduta humana desenvolvidas inescrupulosamente, contra a natureza.

Em decorrência disso, no decorrer dos anos de 1970, a comunidade internacional direcionou seus olhares para o meio ambiente natural, assinando seu estado, e desencadeando um fenômeno global 
identificado como crise ambienta/11. Neste período, foram assinados tratados e convenções entre países, pesquisas científicas apontaram os prováveis efeitos da degradação do meio ambiente natural, mas a mácula ao ambiente natural prossegue na ordem do dia da espécie humana.

Hoje, como nunca, sofre-se pela desertificação de florestas, pela infertilidade do solo, pela extinção de espécies animais e vegetais. Rios desaparecem, lagos secam; a camada de ozônio já não mais comporta uma integral proteção contra os raios ultra violetas, e a Terra enfrenta variações máximas de temperatura que à conduzem ao irrefreável aquecimento global.

Nesse diapasão, o futuro do planeta torna-se uma incógnita. Mesmo que a Ciência e a Política Internacional busquem perspectivas animadoras, a realidade do agir humano desestimula a pretensão de um futuro seguro, sustentável. Se o processo de degradação ambiental continuar, além das fortes temperaturas, futuramente, haverá o total derretimento das calotas polares; elevação do nível dos oceanos; inundações das áreas litorâneas; tempestades; enchentes; catástrofes naturais; desertificação; escassez de água potável; deflagração de doenças (epidemias); inviabilidade do solo para a agricultura; fome; miséria; extinção de espécies vegetais e animais, dentre outras.

É o homem, mais uma vez, alvo dele mesmo... Novamente se encontra na mira de seu poder detrator.

\section{A cooperação na base da proteção ambiental: a conduta cooperacionista nos princípios promulgados pela Declaração do Rio}

As questões relativas ao meio ambiente natural são, notadamente, umas das áreas de interdependência entre os países, posto que uma agressão perpetrada contra o meio ambiente de um país, transcende aos marcos fronteiriços espraiando-se aos vizinhos.

Neste cenário, a Conferência das Nações Unidas sobre Meio Ambiente e Desenvolvimento reuniu-se entre os dias 1 e 15 de junho de 1992, na cidade do Rio de Janeiro, para reafirmar a Declaração da Conferência das Nações Unidas sobre o Meio Ambiente Humano. Sob este feitio, a Declaração do Rio sobre o Meio Ambiente e o Desenvolvimento surgiu com a esperança de constituir uma fidedigna Carta da

11 Freitas, Vladimir Passos. Direito Ambiental em Evolução 2. 8. ${ }^{a}$ ed. São Paulo: Juruá Editora, 2009. 
Terra, que estabelecera os princípios normativos para a defesa e preservação do meio ambiente do planeta.

A despeito de ser considerada como o instrumento internacional utilizado tanto para aferir convergência ao conceito de desenvolvimento sustentável, enunciado pelos princípios 1 e $4^{12}$, e configurado como um direito fundamental dos seres humanos; como para conectar a idéia de desenvolvimento sustentável às necessidades das gerações futuras, em decorrência da equidade inter-gerações, notadamente expressa pelo princípio 3, a Declaração do Rio consagr, acima de qualquer coisa, a atitude cooperacionista como apropriada à preservação e à defesa do meio ambiente natural ${ }^{13}$.

Esta percepção, longe de suscitar idealismo, decorre da disposição integral do princípio $7^{14}$, pelo qual a Declaração atribui graus de responsabilidades aos diferentes grupos de países, e enaltece a necessidade uma cooperação "em espírito de parceria global, para a conservação, proteção e restauração da saúde e da integridade do ecossistema terrestre» ${ }^{15}$.

A Cooperação prevista pela Declaração do Rio desnuda-se do aspecto econômico para enaltecer peculiaridades primitivas do trabalho conjunto de um grupo de países que devem sublimar a consciência da busca por um objetivo comum, qual seja, a preservação da biodiversidade e à proteção dos ecossistemas terrestres.

\section{DECLARAÇÃO DO RIO 92}

\section{Princípio 1}

Os seres humanos estão no centro das preocupações com o desenvolvimento sustentável. Têm direito a uma vida saudável e produtiva, em harmonia com a natureza.

(...)

Princípio 4

Para alcançar o desenvolvimento sustentável, a proteção ambiental constituirá parte integrante do processo de desenvolvimento e não pode ser considerada isoladamente deste. (BRASIL. Legislação de Direito Internacional. São Paulo: Saraiva, 2009. p. 165).

13 Ruiz, José Juste. Derecho Internacional del Medio Ambiente. Madrid: McGrawHill, 1999. p. 24.

14 DECLARAÇÃO DO RIO 92

Princípio 7

Os Estados irão cooperar, em espírito de parceria global, para a conservação, proteção e restauração da saúde e da integridade do ecossistema terrestre. Considerando as diversas contribuições para a degradação do meio ambiente global, os Estados têm responsabilidades comuns, porém diferenciadas. Os países desenvolvidos reconhecem a responsabilidade que Ihes cabe na busca internacional do desenvolvimento sustentável, tendo em vista as pressões exercidas por suas sociedades sobre o meio ambiente global e as tecnologias e recursos financeiros que controlam (BRASIL. Legislação de Direito Internacional. São Paulo: Saraiva, 2009. p. 165).

15 Brasil. Legislação de Direito Internacional. São Paulo: Saraiva, 2009. p. 166. 


\section{Os valores cooperativos como pressuposto de sustentabilidade: a necessidade de altercação da postura do humano diante do meio ambiente natural}

Por tragédia, atualmente, a sociedade ocidental percebe o desenvolvimento econômico como o investimento contumaz em toda a tecnologia originada pelo «homem, no sentido de criar formas de substituir o que é oferecido pela natureza, com vistas, na maior forma das vezes, à obtenção de lucro em forma de dinheiro» ${ }^{16}$. Para o homem, a qualidade de vida está sub-rogada ao grau maior ou menor de riqueza, de liquidez financeira, de possibilidade econômica.

Enquanto se encontre em condições de majorar os valores de sua conta corrente, de cimentar o exercício da atividade econômica dos diferentes segmentos de produção, e materializar seus objetos de desejo, o homem é feliz: está feliz. Sem embargo, a felicidade pela realização econômica e a satisfação material se mostram efêmeras, uma vez que a atitude do homem em relação ao meio ambiente natural tanto compromete a sua existência, como tende a macular seus peculiares padrões de vida.

A relação homem versus meio ambiente é desígnio de futuro, é significado de vida!

Por isto, nos tempos de hoje, o termo sustentabilidade se mostra protagonista no roteiro de todos aqueles que amparam bandeiras de defesa ambiental. Fala-se em desenvolvimento sustentável como um agir corriqueiro intrínseco da não afetação à natureza. Preleciona-se, assim, a sustentabilidade inter-relacionada ao estabelecimento de políticas públicas e ações jurídicas de fiscalização e penalização pelo inadequado uso dos recursos naturais.

Eis o descaminho da in-sus-ten-ta-bi-li-da-de do desenvolvimento!

Proveniente do Relatório Brundtland, editado em 1987 pela Comissão Mundial Sobre Meio Ambiente e Desenvolvimento, da Assembléia das Nações Unidas, o termo desenvolvimento sustentável pressupõe o «desenvolvimento que supre as necessidades da geração presente, sem afetar capacidade das gerações futuras suprirem as suas próprias» ${ }^{17}$.

A partir do instante em que se associa a idéia de desenvolvimento sustentável à otimização dos meios adequados à satisfação de necessidades humanas presentes e futuras, se está a constituir um princípio de responsabilidade que associa os atos de hoje com os feitos de amanhã.

16 Da Silva, 2004, p. 25.

17 Disponível em «http://amaliagodoy.blogspot.com/2008/08/relatrio-brundtland. html», acesso em 29 de junho de 2010. 
Assim sendo, para a proeminência de um efetivo desenvolvimento sustentável, segundo o entretom que Ihe ofereceu o Relatório Brundtland, fundamental encontrar-se um ponto de equilíbrio entre crescimento econômico, equidade sócio-política e proteção do meio ambiente natural.

A boa qualidade do amanhã, mais do que nunca, está condicionada a interação do humano com os fatores preponderantes ao desenvolvimento. Urge, assim, que o homem se posicione diante dos diferentes prodígios que se operam no contexto onde se encontre inserido, e, na medida em que projeta a majoração de sua condição de vida, estabeleça uma forma de agir própria ao estabelecimento de uma postura ecologicamente correta, economicamente viável, socialmente justa e culturalmente aceita ${ }^{18}$.

O desenvolvimento sustentável, então, depende de uma efetiva transformação do homem. Esta transformação, é certo, se consuma quando o homem descobre sua importância diante do meio, a importância do meio onde habita, e, por suposto, a importância daqueles que compartilham do meio com ele ${ }^{19}$. A exemplo do que ocorreu nos primórdios da história, também hoje a consciência pelo valor do coletivo, pela importância do todo, há de resgatar o agir cooperativo como fenômeno social-solidário, intrínseco a vida em comunidade hoje e amanhã.

É, somente sobre a esteira do espírito cooperativo, adstrito a essência dos valores cooperativos editados pela Declaração da Identidade Cooperativa da Aliança Cooperativa Internacional, pelo Congresso de Manchester, em 1995, que homem se descobrirá capaz de subsumir-se com as posturas próprias ao desenvolvimento sustentável.

Antes da eficácia da lei, acima da contumácia dos órgãos públicos de fiscalização e controle, e, com muito mais tenacidade que as sanções administrativas ou judiciárias, o desenvolvimento essencialmente sustentável se mostrará possível a partir do momento em que o homem absorver e praticar os valores cooperativos fundamentais (ajuda mútua, auto-responsabilidade, democracia, igualdade, eqüidade, soli-

18 Miranda, José Eduardo e Corrêa Lima, Andréa. «Universidad y Cooperativismo. Cooperativismo y Universidad: una perspectiva axiológica para la efectiva construcción de la ciudadanía». Boletín de la Asociación Internacional de Derecho Cooperativo. Bilbao: Universidad de Deusto, 2008. p. 168.

19 Miranda, José Eduardo. «Inovación y Cooperativismo. Inovação Social Cooperativa: A Propriedade dos Valores Cooperativos como Instrumento de Resgate e/ou Fortalecimento dos Entornos Debilitados». Boletín de la Asociación Internacional de Derecho Cooperativo. Bilbao: Universidad de Deusto, 2009, p. 129. 
dariedade) e éticos (honestidade, transparência, responsabilidade, vocação social).

Ao prevalecer os valores cooperativos como guia de sua existência, o homem logrará resgatar o «horizonte histórico que estampou possibilidades concretas de construção de uma sociedade justa e igualitária, baseada em princípios de transformação ${ }^{20}$ indispensáveis ao estabelecimento de uma nova postura diante do meio ambienta natural, própria ao relevo dos limites de sua utilização racional, não depredatória.

\section{Referências bibliográficas}

Brasill. Constituição da República Federativa do Brasil. 44 ed. São Paulo: Saraiva, 2010.

BRASIL. Legislação de Direito Internacional. São Paulo: Saraiva, 2009.

BRASIL. Lei 6.938/81. Disponível em www.planaltolgov.br; Acesso em 28 de junho de 2010.

DA SILVA, José Afonso. Direito Ambiental Constitucional. 5. ${ }^{a}$ ed., São Paulo: Malheiros, 2004.

Fiorilıo, Celso Antônio Pacheco. Curso de Direito Ambiental Brasileiro. 11. ${ }^{\text {a ed., }}$ São Paulo: Saraiva, 2010.

Freitas, Vladimir Passos. Direito Ambiental em Evolução 2. 8. ${ }^{a}$ ed. São Paulo: Juruá Editora, 2009.

Luft, Lia. Quando a natureza mata. Veja. São Paulo, Ed. 2156, ano 43, n. ${ }^{\circ} 11$, p. 24, 17, mar. 2010.

Machado, Paulo Affonso Leme. Direito Ambiental Brasileiro. 18. ${ }^{a}$ Ed. São Paulo: Malheiros, 2010.

Mancuso, Rodolfo de Camargo. Interesses Difusos: conceito e legitimação para agir. 6. ${ }^{a}$ ed. São Paulo: RT, 2004.

MIRANDA, José Eduardo e CORRÊA LIMA, Andréa. «Universidad y Cooperativismo. Cooperativismo y Universidad: una perspectiva axiológica para la efectiva construcción de la ciudadanía». Boletín de la Asociación Internacional de Derecho Cooperativo. Bilbao: Universidad de Deusto, 2008.

MIRANDA, José Eduardo. «Inovación y Cooperativismo. Inovação Social Cooperativa: A Propriedade dos Valores Cooperativos como Instrumento de Resgate e/ou Fortalecimento dos Entornos Debilitados». Boletín de la Asociación Internacional de Derecho Cooperativo. Bilbao: Universidad de Deusto, 2009.

MotA, Mauricio Jorge Pereira. O conceito de Natureza e a reparação das externalidades ambientais negativas. Disponível em: http://bdjur.stj.gov. br/xmlui/bitstream/handle/2011/18237/O_Conceito_de_Natureza_e_a_

20 Ibid., p. 131. 
Repara\%C3\%A7\%C3\%A30_das_Externalidades_Ambientais_Negativas. pdf?sequence $=2$. Acesso em 30/05/2010.

RoDRIGUES, Marcelo Abelha. "O Direito Ambiental no século XXI». Revista de Direito Ambiental. São Paulo, ano 13, n. ${ }^{\circ}$ 52, pp. 125-137, out/dez, 2008.

SCHNEIDER, José Odelso. Globalização, Desenvolvimento Sustentável e Cooperativismo. Disponível em «http://www.neticoop.org.uy/lMG/pdf/dc0380. pdf». Acesso em 04/06/2010.

Smanio, Gianpaolo Poggio. Interesses difusos e coletivos. 6. ${ }^{a}$ ed. São Paulo: Malheiros, 2004. 